\title{
Mix Design Considerations of Foamed Bitumen Mixtures with Reclaimed Asphalt Pavement Material
}

\author{
Kranthi Kuna ${ }^{1}$, Gordon Airey ${ }^{2}$, Nick Thom ${ }^{3}$

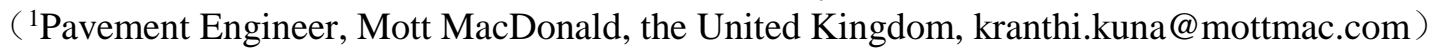 \\ ( ${ }^{2}$ Professor, University of Nottingham, the United Kingdom, gordon.airey@ nottingham.ac.uk) \\ (32Lecturer, University of Nottingham, the United Kingdom, nicholas.thom@nottingham.ac.uk)
} not to be applicable.

Keywords: Foamed bitumen treated mixes, mixing and compaction water content, reclaimed asphalt pavement, mechanical properties, volumetrics, water-bitumen interaction

$\begin{array}{ll}\text { CBM } & \text { Cold Bituminous Mixtures } \\ \text { ER } & \text { Expansion Ratio } \\ \text { FB } & \text { Foamed Bitumen } \\ \text { FBM } & \text { Foamed Bitumen Mixture } \\ \text { FWC } & \text { Foaming Water Content } \\ \text { HL } & \text { Half-Life } \\ \text { HMA } & \text { Hot Mix Asphalt } \\ \text { ITS } & \text { Indirect Tensile Strength } \\ \text { ITSM } & \text { Indirect Tensile Stiffness Modulus } \\ \text { MDD } & \text { Maximum Dry Density } \\ \text { MWC } & \text { Mixing Water Content } \\ \text { NAT } & \text { Nottingham Asphalt Tester } \\ \text { Nesign }_{\text {Design number of gyrations }} & \text { Design } \\ \text { OWC } & \text { Optimum Water Content } \\ \text { RAP } & \text { Reclaimed Asphalt Pavement } \\ \text { VA } & \text { Virgin Aggregate } \\ \text { VMA } & \text { Voids in Mineral Aggregates }\end{array}$




\section{INTRODUCTION}

Unlike for HMA (Hot Mix Asphalt), there is no universally accepted mix design method for FBMs. Most of the agencies [1,2] which use FBMs have their own mix design procedures which are the result of numerous efforts over decades [3-9]. In spite of all these efforts, foamed bitumen application in cold recycling in the United Kingdom suffers from the lack of a standardised mix design procedure. As a result, the mix design parameters such as foam characteristics, mixing, compaction, curing and testing that are being adopted are far from being standardised. To overcome this, research had been undertaken at the University of Nottingham by Sunarjono (2008) [10] to develop a mix design procedure by identifying critical mix design parameters. The research by Sunarjono focussed on the influence of the bitumen type, the foaming conditions, foam characteristics and mixer type on the mechanical properties of FBM. The major outcomes of the work were recommendations for producing an optimised FBM in terms of mixer type and usage, selection of binder type, bitumen temperature, and foam characteristics. Therefore this present study focussed on other mix design parameters such as foamed bitumen content, MWC, and compaction effort. Thus, the primary objective of the present study is to propose a practical and consistent mix design procedure with emphasis on the use of the gyratory compactor.

The amount of water during mixing and compaction is considered as one of the most important parameters in FBM mix design $[11,12]$. The MWC of FBM is defined as the water content in the aggregate when the foamed bitumen is injected. This helps in dispersion of the mastic in the mix [3, 13]. However, too much water causes granular agglomerations which do not yield optimum dispersion of the mastic in the mix $[14,15]$. In view of this fact many studies have been focussed on the optimisation of MWC. Lee (1981) [16] and Bissada (1987) [17] optimised MWC with reference to Marshall stability and found that the optimum MWC is very much dependent on other mix design variables such as the amount of fines and bitumen content. Sakr and Mank (1985) [18] related the MWC to other mix design variables and recommended a relationship among them to obtain optimum MWC. However, this work was performed on a foamed bitumen stabilised sand mixture which did not have any coarser fractions of aggregate. Moreover, the work was based on optimising the density, without considering any mechanical properties. The concept of optimum fluid content was later borrowed from emulsion mix design in which the sum of the water and bitumen content should be close to OWC $[5,19]$ obtained by the modified Proctor test. This concept considers the lubricating action of the binder in addition to that of water. Thus the actual water content of the mix for optimum compaction is reduced in equal measure to the amount of bitumen incorporated. However, the work of Kim and Lee (2006) [8] and Xu et al., (2012) [12], who optimised MWC based on both density criteria and fundamental tests (ITS and tri-axial tests) on FBM Marshall specimens, calls into question the lubricating action of bitumen in the mix. Although the above discussed works are very informative, they have their limitations and little attention has been paid to optimising MWC using gyratory compaction. Therefore, the present work was aimed at obtaining a rational range of MWC for mix design with the help of fundamental tests such as ITS (BS EN 12697-23:2003) and ITSM (DD 213: 1993) on FBM specimens.

Because of the presence of the water phase, the compaction mechanism of FBMs is very different from that of HMA. Various laboratory compaction methods such as Marshall compaction [5, $8,12,13]$, vibratory compaction [3, 7, 20], gyratory compaction [13, 21-23] have been used in the past. There are very well-established guidelines for Marshall compaction [2] and vibratory compaction $[24,25]$. However, there are no set guidelines for a gyratory compaction method for FBMs in terms of compaction effort (number of gyrations, gyration angle and applied pressure). Past studies have evaluated the feasibility of using laboratory gyratory compaction on FBM (Table 1). In these studies efforts were made to obtain the design compaction effort in terms of compaction pressure, gyration angle and number of gyrations. The compaction pressures recommended by Australian guidelines $(0.24 \mathrm{MPa}$ and $1.38 \mathrm{MPa}$ from Table 1) were taken forward in SHRP (Strategic Highway Research Program) work on HMA, resulting in recommendations of $0.6 \mathrm{MPa}$ and $1.25^{\circ}$ angle of gyration. Jenkins et al., (2004) [22]'s tabulated conditions were based on a single water content and a single foamed bitumen content. From preliminary trials it was found that the 30 gyrations recommended by Kim and Lee were too few to achieve modified Proctor densities. The ideal compaction effort has to produce mix densities that are achieved in the field. Therefore, modified Proctor density which is used worldwide to represent field compaction is used as a reference 
in the present study. It was understood from the past studies [10] that the permanent deformation behaviour of FBMs is sensitive to the number of gyrations, which might be attributed to the arrangement of the aggregate skeleton. Hence efforts were made to propose a design number of gyrations $\left(\mathrm{N}_{\text {design }}\right)$ and it was decided to use the SHRP recommended compaction conditions which are $600 \mathrm{kPa}$ compaction pressure and $1.25^{\circ}$ angle of gyration. During the optimisation of MWC, the compactability of these mixtures during modified Proctor compaction and Gyratory compaction was also studied.

\section{Table 1 Gyratory compaction effort on FBMs by different researchers}

\begin{tabular}{|l|c|c|c|l|}
\hline \multicolumn{5}{|c|}{ Summary of gyratory compaction effort on FBM by different researchers } \\
\hline & $\begin{array}{l}\text { Number of } \\
\text { gyrations (N) }\end{array}$ & $\begin{array}{l}\text { Compaction } \\
\text { pressure } \\
\text { (MPa) }\end{array}$ & $\begin{array}{l}\text { Gyration } \\
\text { angle } \\
\text { (degrees) }\end{array}$ & Reference density \\
\hline Brennan (1983) [13] & 20 & 1.38 & N/A & $2.25 \mathrm{~kg} / \mathrm{m}^{3}$ \\
\hline Maccarrone et al.1994 [21] & 85 & 0.24 & 2 & Field density \\
\hline Jenkins et al. (2004) [22] & 150 & 0.6 & 1.25 & $\begin{array}{l}\text { Modified proctor } \\
\text { density }\end{array}$ \\
\hline Kim and Lee (2006) [8] & 30 & 0.6 & 1.25 & $\begin{array}{l}\text { Marshall density } \\
\text { (75 blows) }\end{array}$ \\
\hline & & & & $\begin{array}{l}\text { Australian } \\
\text { guidelines for } \\
\text { HMA }\end{array}$ \\
\hline Saleh (2006b) [23] & 80 & 0.24 & 2 & \multicolumn{2}{|l}{} \\
\hline
\end{tabular}

\section{MATERIALS}

Alongside the bitumen and virgin aggregate, particular attention was given to RAP characterization. This is important as RAP characteristics have considerable effect on the mix design of cold bitumen mixtures (CBM) because of the amount of variability associated with RAP in terms of source, production, storage and usage. However, it has to be noted that studies have found that RAP is less variable that virgin aggregate if its storage or stockpiling is well managed and that bituminous mixtures produced with high RAP content are actually less variable [26].

It is known that in mix design of HMA containing RAP, the aged bitumen in the RAP is often considered as an active component during the mixing and the bitumen in the new bituminous mixture is adjusted using blending charts. This approach is rational as the mixing of HMA is usually carried out at temperatures above $140^{\circ} \mathrm{C}$ where the aged bitumen in the RAP is less viscous. However, this is not the case in CBMs containing RAP, in which mixing and compaction is carried out at ambient temperatures which are much lower than the temperature required for softening the aged bitumen. Hence, each of the different agencies treat the RAP differently in their CBM mix design procedure. Some agencies factor the contribution of the aged bitumen present in RAP while others do not. This conflicting consideration is due to the unknown effect of the properties of aged bitumen in the RAP on the properties of the added fresh bitumen and on the amount of bitumen to be added. To address these issues research is ongoing under the initiative of the CR (Cold Recycling) task group (TG6) of RILEM (TC-237 SIB). Most of the tests that were performed on RAP were part of the inter laboratory round robin testing programme on RAP characterization as a part of TG6.

\subsection{Bitumen}

In HMA mix design, the expected traffic and the regional climate influence the selection of the bitumen type. However in FBM mix design, foamability (foaming potential) of the bitumen and the mixture compactability also need to be considered during selection of the bitumen. In the present study a 70/100 penetration grade bitumen ( $90 \mathrm{dmm}$ penetration at $25^{\circ} \mathrm{C}$ and softening point of $45^{\circ} \mathrm{C}$ ) was used. 


\section{$2.2 \quad$ Virgin aggregates}

4

The virgin mineral aggregate used in this study was carboniferous limestone from Derbyshire, UK. The aggregates were stored separately in stockpiles of size fractions of $20 \mathrm{~mm}, 14 \mathrm{~mm}, 10 \mathrm{~mm}$, $6 \mathrm{~mm}$, dust $(0.063 \mathrm{~mm}<$ dust $>6 \mathrm{~mm})$ and filler $(<0.063 \mathrm{~mm})$. The stocks were batched to attain the design gradation for each of the mixes. Particle size distribution was determined according to BS EN 933-1:1997. The design gradation adopted in the present study is as plotted in Figure 1.

\subsection{Reclaimed Asphalt Pavement}

The RAP material used in the present study was supplied from a UK asphalt contractor. The RAP was from a single source and from a well-managed stockpile before being delivered to the laboratory. The RAP aggregate material from the quarry was initially air dried at room temperature in the laboratory at $20 \pm 2^{\circ} \mathrm{C}$ for 24 hours and then placed in a thermostatically controlled oven at a temperature of $40^{\circ} \mathrm{C}$ for 24 hours and thereafter sieved into different sizes to improve the consistency of the material and to reduce variability in the RAP. These separated fractions were stored in sealed containers for further use.

The basic properties that are recommended to be measured on RAP for use in HMA mix design are aggregate gradation before and after bitumen recovery, bitumen content, bulk specific gravity of recovered aggregates and recovered binder properties. Obtaining these properties is particularly important in the mix design of CBMs as they often contain high amounts of RAP. In addition to the above mentioned tests, fragmentation and cohesion tests were recommended by the CR task group (TG6). These two tests are discussed in the following sections.

\subsubsection{Analysis on RAP constituents}

To determine mass/volume parameters such as VMA (Voids in Mineral Aggregate), the aggregate volume properties have to be known. When RAP materials are included in the mixtures, the determination process becomes more complicated as it is necessary to calculate the bulk specific gravity of each aggregate component (virgin and RAP aggregate). Measuring specific gravity of the RAP aggregate requires extracting the aggregate, recovering the bitumen, sieving the RAP aggregate into coarse and fine fractions, and determining the specific gravity of each fraction. Before bitumen recovery, the initial gradation, which is a basic characteristic of RAP, was ascertained in accordance with BS EN 933-48 2:2012. To evaluate constituents of the RAP, a composition analysis was conducted in accordance with BS 598-102:2003. The aggregates from the RAP were extracted by centrifuge using Dichloromethane (DCM) as recommended by the standard. After extracting bitumen from the RAP, sieve analysis was carried out on the extracted aggregates. The gradation of the RAP including that of the recovered aggregate is shown in Figure 1.

Once the binder was extracted and recovered from the RAP materials, its properties such as penetration and softening point were determined. To determine the chemical composition of the recovered bitumen BS 2000 Part 143:2004 was followed in which the asphaltene contents were precipitated using heptane $\left(\mathrm{C}_{7} \mathrm{H}_{16}\right)$. The results of asphaltene content and physical properties of recovered bitumen are presented in Table 2. 


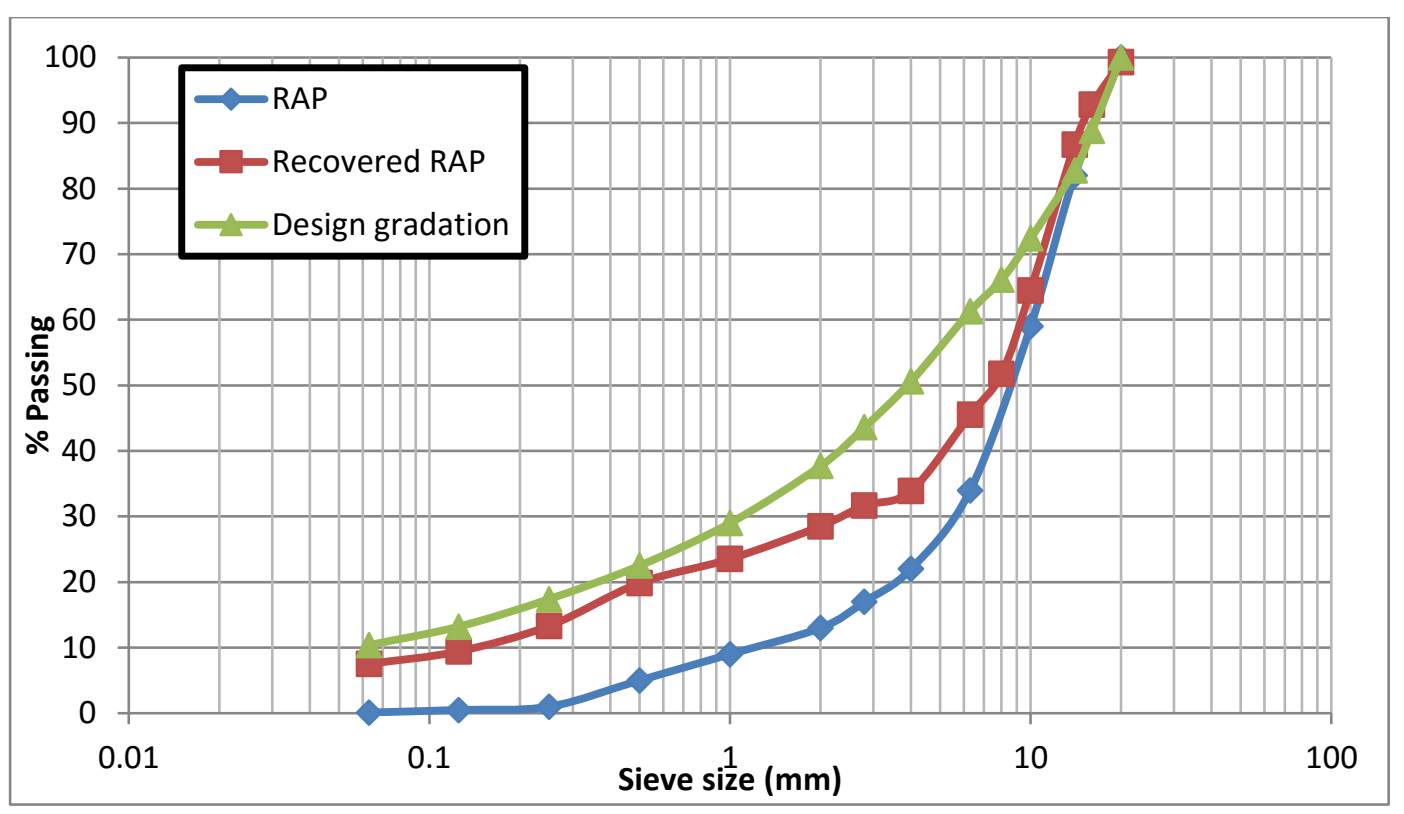

Figure 1 Gradation of RAP and recovered aggregate

Table 2 Properties of recovered bitumen from 3 samples of RAP

\begin{tabular}{|c|l|l|l|l|l|}
\hline Recovered bitumen properties & RAP1 & RAP2 & RAP3 & Average & Std. Dev. \\
\hline $\begin{array}{c}\text { Binder Content (\%) (BS 598- } \\
102: 2003, \text { BS 598-101:2004) }\end{array}$ & 4.5 & 4.7 & 4.4 & 4.5 & 0.1 \\
\hline $\begin{array}{c}\text { Penetration (dmm) at } 25^{\circ} \mathrm{C} \\
(\text { ASTM D5-05A) }\end{array}$ & 20 & 16 & 17 & 17.7 & 1.7 \\
\hline $\begin{array}{c}\left.\text { Softening Point ( }{ }^{\circ} \mathrm{C}\right)(\mathrm{ASTM} \\
\text { D36-95(2000)) }\end{array}$ & 64.2 & 67.3 & 67.8 & 66.4 & 1.6 \\
\hline $\begin{array}{c}\text { Viscosity at } 135^{\circ} \mathrm{C}(\mathrm{mPa}-\mathrm{s})(\mathrm{BS} \\
\text { EN 13302:2003) }\end{array}$ & 1077 & 1154 & 1189 & 1140 & 46.8 \\
\hline $\begin{array}{c}\text { Asphaltene content (\%) (BS } \\
2000-143: 2004)\end{array}$ & 35 & N/A & N/A & N/A & N/A \\
\hline
\end{tabular}

4

\subsubsection{Homogeneity of RAP}

Verifying the homogeneity of RAP properties is an important step in quality control when designing bituminous mixtures with RAP. This is particularly true in cold recycling in which high amounts of RAP are often incorporated. Moreover, the mean values of the RAP properties are used to adjust the required grading curve and to select the virgin bitumen. Therefore, homogeneity of RAP in terms of gradation, bitumen content and the properties of recovered bitumen such as penetration, softening point and viscosity was evaluated. Figure 2 shows the gradation of different samples of the RAP before and after aggregate extraction. The figure also shows the standard deviation for each particle size for both RAP and extracted aggregates. As can be seen from the figure the standard deviations at all sieve sizes are reasonably low (maximum standard deviation is found to be $2.2 \%$ ). It should be noted that the extracted aggregates from the RAP were found to be less variable than the RAP before bitumen recovery as seen in Figure 2.

Homogeneity of RAP was also evaluated with reference to the limits suggested by NCHRP report 752 [27] and guidelines for the use of RAP in Lithuania [28]. The standard deviation of recovered bitumen properties and extracted aggregate properties along with homogeneity limits specified by the above mentioned references are presented in Table 3. As can be seen from the table the standard deviations are well below the specified maximum limits which suggests the homogeneity of the RAP used in the study was acceptable. It has to be noted that both the references suggest testing 
of at least 10 samples. However in the present study only 3 samples were tested for homogeneity as recommended by RILEM TG6 technical committee.

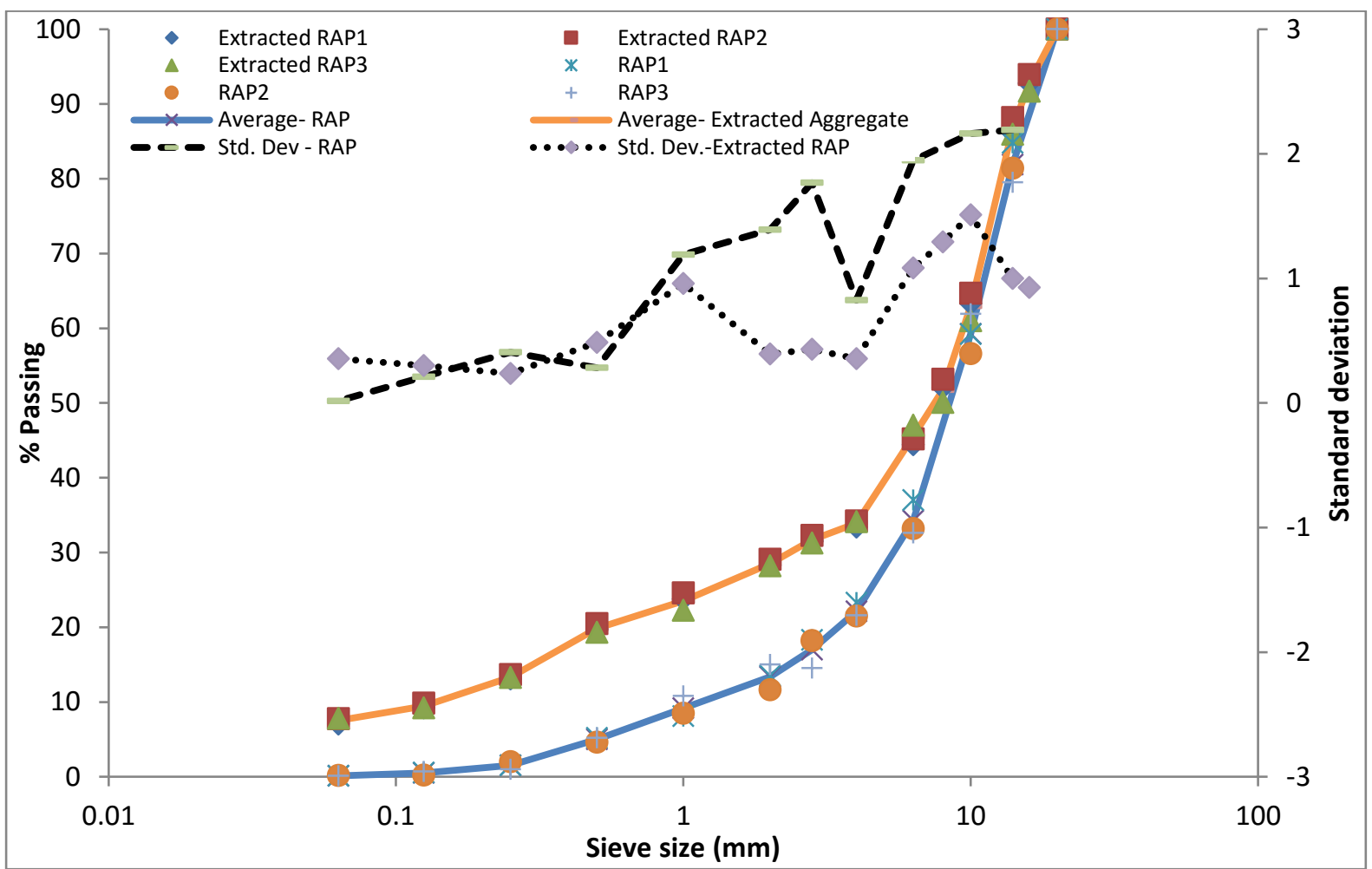

Figure 2 Homogeneity evaluation of RAP in terms of gradation

6 Table 3 Homogeneity limits for RAP stockpile

\begin{tabular}{|l|l|l|l|}
\hline $\begin{array}{l}\text { Properties of RAP constituents after } \\
\text { bitumen recovery }\end{array}$ & $\begin{array}{l}\text { Standard } \\
\text { Deviation }\end{array}$ & $\begin{array}{l}\text { Allowable } \\
\text { Standard } \\
\text { deviation }\end{array}$ & Reference \\
\hline Binder Content $(\%)$ & 0.1 & 0.5 & NCHRP-752[27] \\
\hline Penetration $(\mathrm{dmm})$ at $25^{\circ} \mathrm{C}$ & 1.7 & 4 & Lithuania[28] \\
\hline Softening Point $\left({ }^{\circ} \mathrm{C}\right)$ & 1.6 & 2 & Lithuania \\
\hline Aggregate gradation-all sieves (max) & 1.5 & 5 & NCHRP-752 \\
\hline Aggregate gradation-0.063mm sieve & 0.35 & 1.5 & NCHRP-752 \\
\hline
\end{tabular}

\section{$8 \quad$ 2.3.3 Fragmentation test on RAP}

The fragmentation test is an impact test which involves a normalised mass falling from a height for a fixed number of times onto the surface of the RAP and thereafter evaluating the amount of material passing the $1.6 \mathrm{~mm}$ sieve. The coefficient of fragmentation is the ratio of the weight of the material before impact and the weight of the material passing the $1.6 \mathrm{~mm}$ sieve after impact. The available guidelines for this test are from French standard P 18-574: Granulats - Essai de fragmentation dynamique. The standard requires the test to be carried out at different temperatures on the different sizes of the aggregate. As RAP includes bitumen, different results are expected at different temperatures (temperature sensitive material). The standard recommends using a $14 \mathrm{~kg}$ mass, 17 lifted mechanically and allowed to fall under gravity on to the top surface of a RAP sample placed in 
a steel mould of $100 \mathrm{~mm}$ diameter and $50 \mathrm{~mm}$ height. The number of blows depends on the size of the RAP in the mould. A similar impact test is also recommended in BS EN 1097-2:2010, which requires material to be placed in a steel cylinder and subjected to ten impacts from a hammer of mass $50 \mathrm{~kg}$ freely falling from $400 \mathrm{~mm}$ height. The amount of fragmentation caused is measured by sieving the tested material using five specified test sieves. However in the present case modified Proctor compaction (BS EN 13286-2: 2004) which is also an impact test was employed as recommended by RILEM TG6 technical committee.

The modified Proctor compaction involves 56 blows with a standard rammer on each of 5 layers. The rammer and mould specification are as mentioned in BS EN 13286-2: 2004. The RAP was tested in different size fractions, $14 \mathrm{~mm} / 20 \mathrm{~mm}, 10 \mathrm{~mm} / 14 \mathrm{~mm}$ and $4.5 \mathrm{~mm} / 10 \mathrm{~mm}$ and at different temperatures, $5^{\circ} \mathrm{C}, 20^{\circ} \mathrm{C}$ and $40^{\circ} \mathrm{C}$. The test was performed after conditioning the material for 4 hours at the test temperature. The results of the tests are presented in Figure 3. As can be seen from the figure, the coefficient of fragmentation has not followed any trend, which indicates that the test results are not, as might have been expected, temperature dependent.

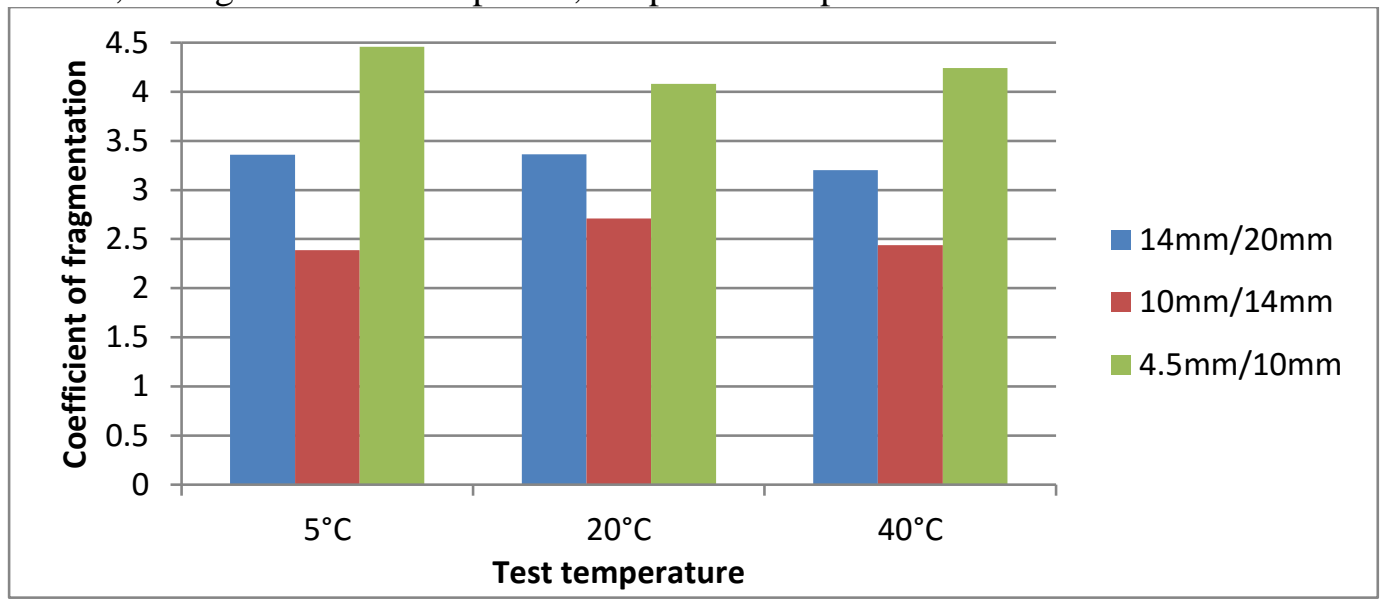

Figure 3 Fragmentation test results on RAP

\subsubsection{Cohesion test on RAP}

Further to the above tests, to ascertain if the bitumen in the RAP could be classified as "active" or "inactive", an indicative test was conducted, which is currently under investigation by the RILEM committee. This involved conditioning a sample of RAP for 4 hours at $70^{\circ} \mathrm{C}$ followed by the manufacture of three $100 \mathrm{~mm}$ diameter by $63.5 \mathrm{~mm}$ high specimens using Marshall compaction with 50 blows per face. After compaction, Indirect Tensile Strength (ITS) tests in accordance with BS EN $12697-23$ were carried out at $20^{\circ} \mathrm{C}$ and then in wet conditions, soaked at $20^{\circ} \mathrm{C}$ for 24 hours. If the soaked ITS $\leq 100 \mathrm{kPa}$ or the specimens do not hold together after compacting at $70^{\circ} \mathrm{C}$, the RAP is considered to be inactive. For comparison, the test was also conducted with RAP conditioned at $140^{\circ} \mathrm{C}$. In all cases, the values exceeded $100 \mathrm{kPa}$ indicating that the binder in the RAP used in the study can be classified as active. The results are presented below in Figure 4.

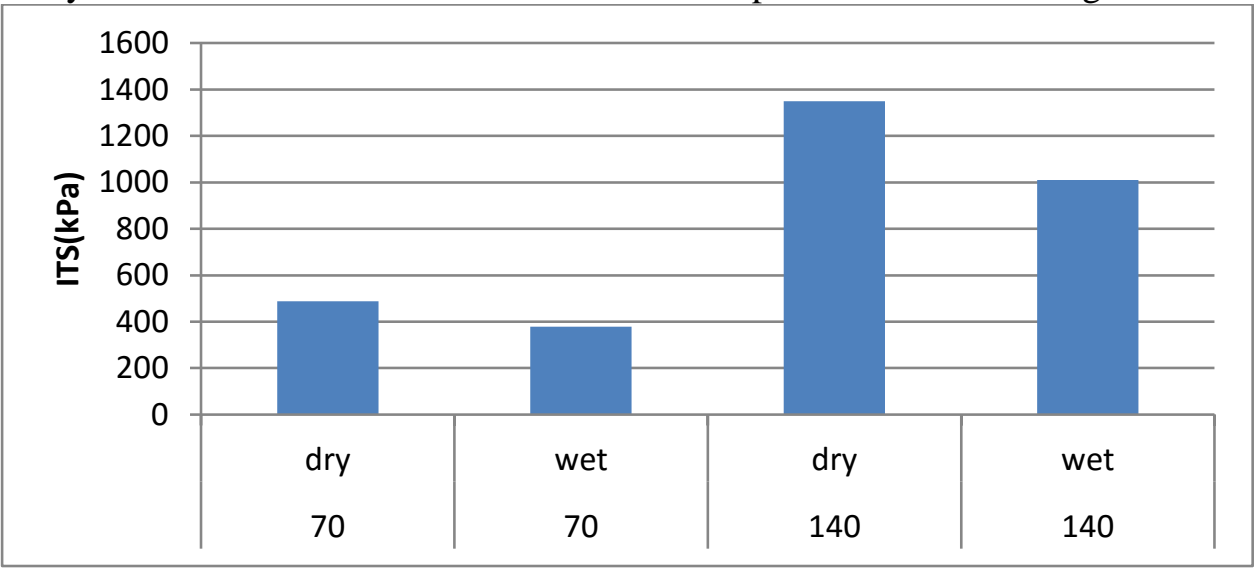

Figure 4 Cohesion test results on RAP 


\section{METHODOLOGY}

A detailed experimental design was prepared for the study and is tabulated in Table 4. The factors were selected by considering the findings of previous work done at the University of Nottingham [10] and Asphalt Academy (2009) [25]. The MWC was optimised on gyratory compacted specimens that were compacted to modified Proctor densities. The role of water and bitumen during gyratory and modified Proctor compaction can be analysed by a weight-volume relationship. In the present study, VMA, which is an indicator for compactability is used to understand the role of bitumen and water during compaction. VMA of a compacted specimen can be calculated using Eq. (1).

$$
\begin{aligned}
& \text { VMA }(\%)=100-\left(\rho_{\mathrm{b}} * \mathrm{P}_{\mathrm{s}}\right) / \rho_{\mathrm{s}} \\
& \text { Where } \rho_{\mathrm{b}} \text { is the bulk density of the specimen } \\
& \rho_{\mathrm{s}} \text { is the bulk density of the aggregate (solids) } \\
& \mathrm{P}_{\mathrm{s}} \text { is aggregate content by weight of mix }(\%)
\end{aligned}
$$

For Hot Mix Asphalt, HMA, Eq. (1) can be applied as it is, as it has only two components, aggregate and bitumen. The weight and volume constituents remain constant throughout and volumetric relationships such as bulk density remain independent of time of test. However, for FBMs in addition to aggregate and bitumen, water also exists in the mixture. But these FBMs lose water with time as can be seen in Figure 5. The figure represents change in constituents (solids, bitumen, water and air) per unit weight and unit volume over time (immediately after compaction (a), after a period of time (b) and in the dry state (c)). As can be seen in the figure neither weight nor volume constituents remain constant with time. This is because of the presence of the water phase in these mixtures. Hence, dry density $\left(\rho_{\mathrm{d}}\right)$ was used instead of bulk density $\left(\rho_{\mathrm{b}}\right)$ in Eq (1) to obtain VMA. Magnitude of

\begin{tabular}{|c|c|c|}
\hline $\begin{array}{l}\text { Mix design } \\
\text { parameter }\end{array}$ & factorial levels & Remarks \\
\hline Bitumen type & 90pen (70/100 grade) & constant throughout the experiment \\
\hline \multirow{2}{*}{$\begin{array}{l}\text { Target Foam } \\
\text { Characteristics }\end{array}$} & $\mathrm{ER}=10$ & \multirow{2}{*}{$\begin{array}{c}\text { Asphalt Academy (2009) and } \\
\text { Sunarjono (2008) }\end{array}$} \\
\hline & HL (seconds) $=6$ & \\
\hline \multirow{2}{*}{ Foaming conditions } & Temperature $\left({ }^{\circ} \mathrm{C}\right): 170$ & \multirow{2}{*}{ constant throughout the experiment } \\
\hline & FWC $(\%): 3$ & \\
\hline Mixer type & Pug mill type mixer & constant throughout the experiment \\
\hline Aggregate type & limestone & constant throughout the experiment \\
\hline Aggregate gradation & 20mm (maximum size) & $\begin{array}{l}\text { Asphalt Academy (2009), constant } \\
\text { throughout the experiment }\end{array}$ \\
\hline MWC & $\%$ of OWC: $65,75,85,95$ & variable to be optimised \\
\hline $\begin{array}{l}\text { foamed bitumen } \\
\text { content }\end{array}$ & $\%$ of total weight: $2,3,4,5$ & variable to be optimised \\
\hline
\end{tabular}
constituents per unit of FBM with MWC of $85 \%$ of OWC and bitumen content of $4 \%$ can be seen in Table 5.

Table 4 Experimental design for mix design parametric study 


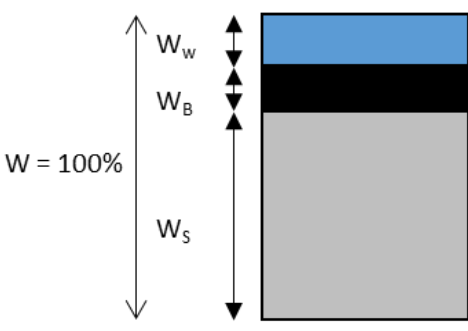

(a)

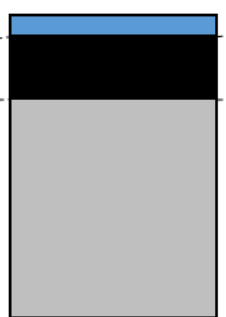

(b)

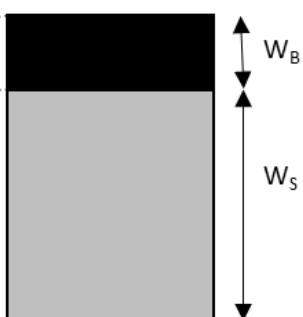

(c)

1

1. Constituents per unit weight in FBM

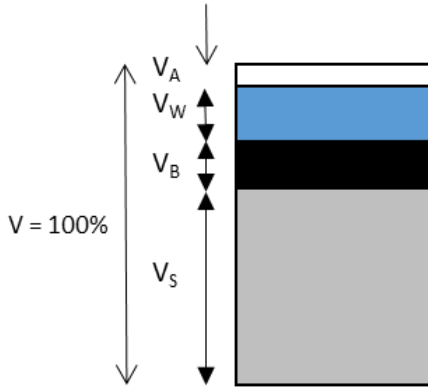

(a)

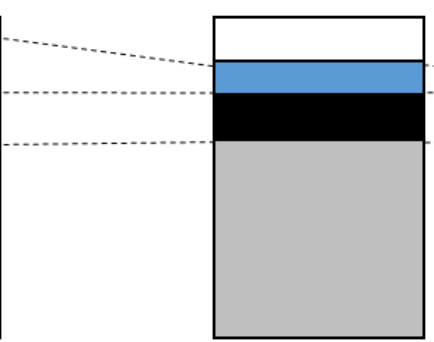

(b)

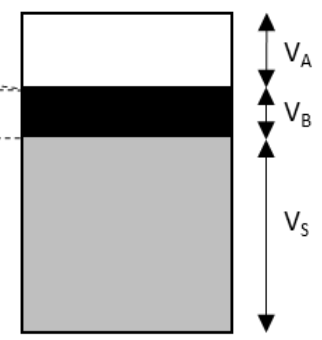

(c)

2. Constituents per unit volume in FBM

Figure 5 Change in weight and volume constituents per unit of FBM

Note: Figure is not to the scale

Table 2 Weight and volume constituents per unit of FBM

Constituents per unit of FBM with MWC of $85 \%$ of OWC and bitumen content of $4 \%$

\begin{tabular}{|l|l|l|l|l|l|l|}
\hline & \multicolumn{2}{|l|}{$\begin{array}{l}\text { (a) Immediately after } \\
\text { compaction }\end{array}$} & \multicolumn{2}{l|}{$\begin{array}{l}\text { (b) } 48 \text { hours at } 20^{\circ} \mathrm{C} \\
\text { after compaction* }\end{array}$} & \multicolumn{2}{l|}{ (c) dry state } \\
\cline { 2 - 7 } & $\begin{array}{l}\text { Weight } \\
(\%)\end{array}$ & $\begin{array}{l}\text { Volume } \\
(\%)\end{array}$ & $\begin{array}{l}\text { Weight } \\
(\%)\end{array}$ & $\begin{array}{l}\text { Volume } \\
(\%)\end{array}$ & $\begin{array}{l}\text { Weight } \\
(\%)\end{array}$ & $\begin{array}{l}\text { Volume } \\
(\%)\end{array}$ \\
\hline Air & 0 & 4.4 & 0 & 10.4 & 0 & 15.7 \\
\hline Water & 5.5 & 11.3 & 2.5 & 5.3 & 0 & 0 \\
\hline Bitumen & 4 & 8.2 & 4.1 & 8.2 & 4.2 & 8.2 \\
\hline Solids & 90.5 & 76.1 & 93.4 & 76.1 & 95.8 & 76.1 \\
\hline
\end{tabular}

* First 24 hours in gyratory mould at $20^{\circ} \mathrm{C}$

7

\subsection{Mixing}

Foamed Bitumen begins to collapse rapidly once it comes into contact with relatively cold 
most often applied directly from the laboratory foaming plant to the aggregate as it is being agitated in the mixer. As different mixers can produce up to a $25 \%$ difference in strength [25] selection of an appropriate mixer is very important in the production of FB mix. It is always recommended to utilise a mixer that simulates site mixing. Pug mill drum mixers and milling-drum mixers are the most commonly used mixers on site for the production of FBM. These mixers provide sufficient volumes in the mixing chamber and energy of agitation to ensure better mixing [3]. A pug mill type mixer is therefore recommended for production of FBM representative of the field [29]. Hence, a twin shaft pug mill mixer was adopted in this work (operated at $20 \pm 2^{\circ} \mathrm{C}$ ). Mixing time should be in accordance with the time required by the bitumen foam to collapse. In the laboratory a mixing time of 60 seconds has been recommended [17] which is longer than in situ mixing but simulates the difference in the energy of the laboratory mixer and field plant and the same (60 seconds mixing time) was adopted in this study.

The optimisation of MWC was carried out on specimens compacted using the gyratory compactor to densities that were obtained by modified Proctor compaction. Targeting modified Proctor densities meant that all specimens were compacted to the same compaction effort. This approach was considered suitable as it is not appropriate to compact mixtures with different water contents to the same density as they would need very different compaction efforts. For example, mixtures with $100 \%$ of OWC ( $6.5 \%$ by weight of mixture) needed 200 gyrations to compact to MDD while a mixture with $65 \%$ of OWC (4.25\% by weight of mixture) required around 340 gyrations. Hence, modified Proctor compaction was carried out on aggregate and water mixtures in accordance with BS EN 13286-2: 2004. The results of the modified Proctor compaction can be seen Figure 6, including results of modified Proctor compaction on mixtures with RAP. As can be seen from Figure 6 , the OWC for $100 \%$ VA mixtures was found to be $6.5 \%$ and for mixtures with RAP the OWC was around $6 \%$.

Once OWC from modified Proctor compaction had been obtained, mixing was carried out with varying water content $(65 \%, 75 \%, 85 \%$ and $95 \%$ of OWC, which corresponds to $4.2 \%, 4.9 \%, 5.5 \%$ and $6.2 \%$ water content in the mixture) and varying $\mathrm{FB}$ content $(2 \%, 3 \%, 4 \%$, and $5 \%)$. These mixtures were compacted using modified Proctor compaction; densities were obtained and the results for $100 \%$ VA are presented in Figure 7. After obtaining the densities, these possible combinations of mixtures were mixed and compacted using a gyratory compactor (angle of gyration $1.25^{\circ}$ and compaction pressure $600 \mathrm{kPa}$ ) using different numbers of gyrations to obtain the achieved modified Proctor densities. Gyratory compacted moulds after compaction were kept at room temperature for 24 hours and then the specimens were extracted. The extracted specimens were cured at $40^{\circ} \mathrm{C}$ and the water content of the specimen was monitored over time. Mechanical tests were carried out (at ambient room temperatures of $20 \pm 2^{\circ} \mathrm{C}$ ) on the cured specimens after 3 to 5 days depending on the amount of water in the specimen. The tests were carried out on all specimens at approximately the same water content (between $0.6 \%$ and $0.65 \%$ ) to eliminate the effect of water content on the measured mechanical properties. The effect of mixing water content on the mechanical properties can be seen in the plots in Figure 8.

The mechanical properties (ITSM, ITS-dry and ITS-wet) of gyratory-compacted and cured specimens are plotted against MWC in terms of \% of OWC in Figure 8. Each ITSM value in the plot is an average of tests on 8 specimens and ITS-dry and ITS-wet are averages of 4 specimens. The properties were all measured at the same water content $(0.6-0.65 \%)$. As can be seen from the figures, the approximate peak ITSM values were $85 \%$ of OWC, except for $2 \% \mathrm{FBM}$ (FBM with $2 \%$ FB content). When ITS-dry results were considered, the optimum MWC was seen at $85 \%$ of OWC for $2 \% \mathrm{FBM}$ and $3 \% \mathrm{FBM}$; and for 4\% FBM and 5\% FBM the peak was at 75\%. For ITS-wet values the optimum was found at $85 \%$ except for 5\% FBM. Overall, the optimum MWC for all mixtures was consistently found to lie between $75 \%$ and $85 \%$ of OWC. 


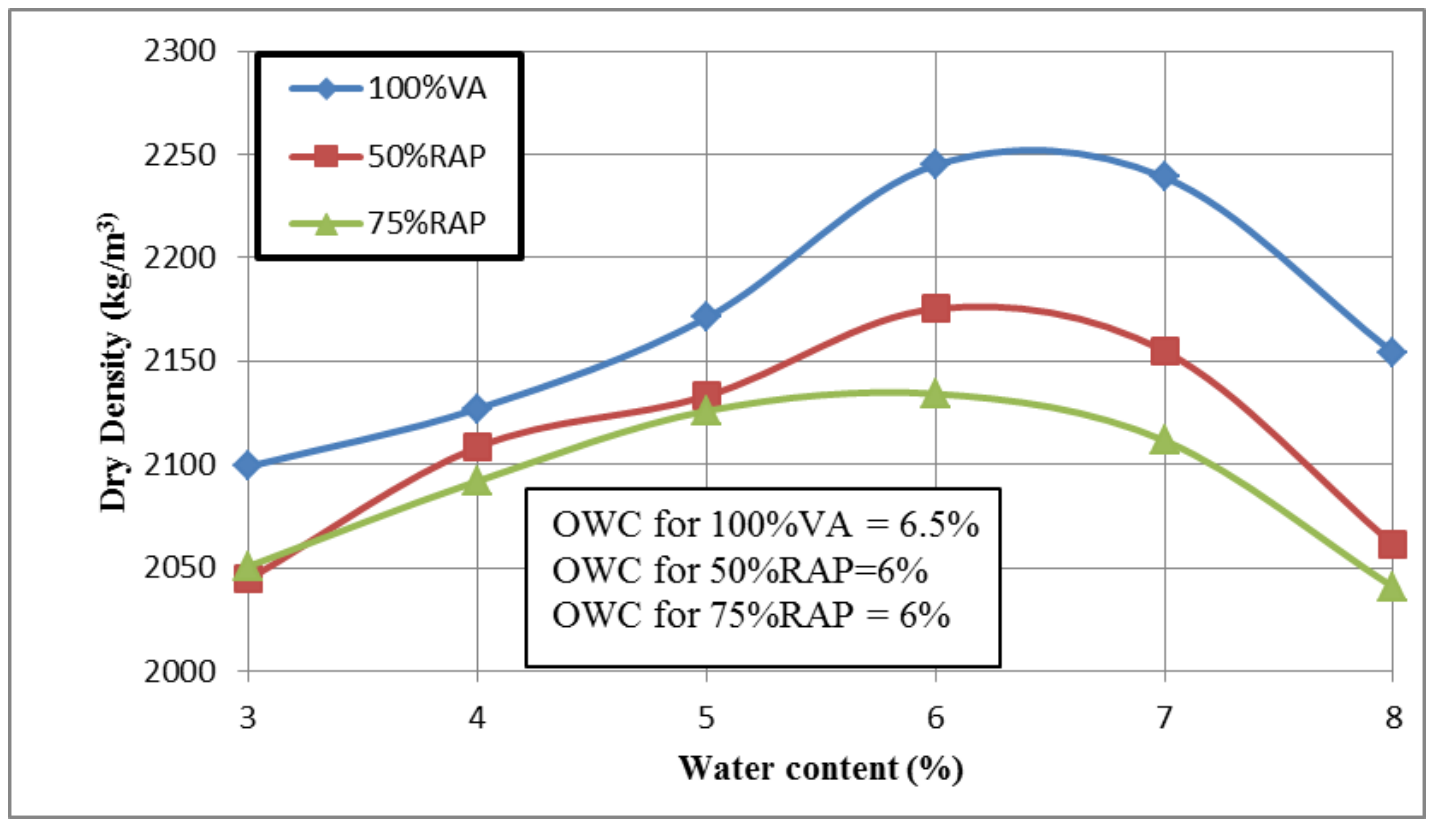

1

Figure 6 Modified Proctor test results on aggregate and water (only) mixtures

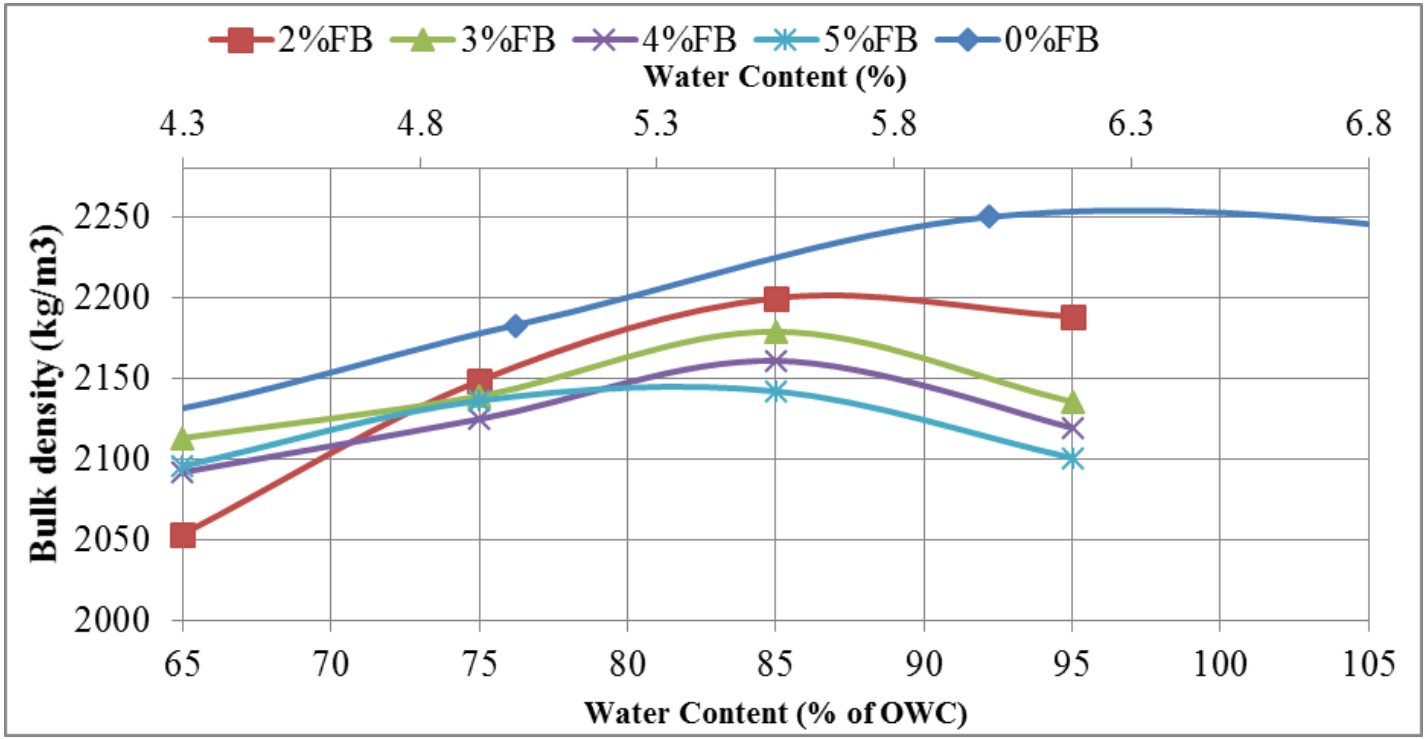

4 Figure 7 Modified Proctor compaction results on 100\%VA-FBM with varying FB and water 5 content 


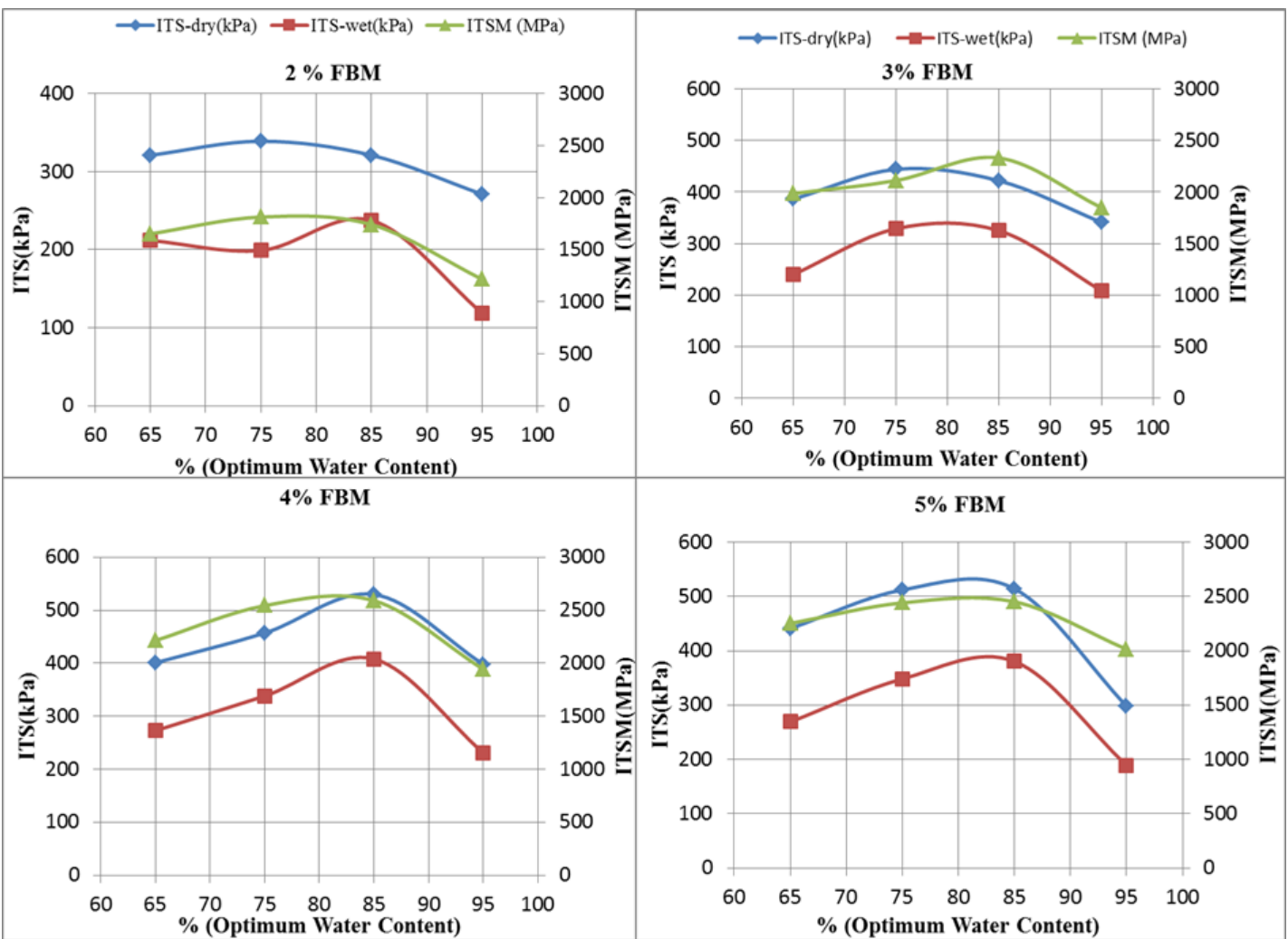

Figure 8 Mechanical properties of $100 \%$ VA- FBM with varying FB and water content

\subsubsection{Compaction effort}

As discussed in the earlier sections, one of the objectives of this study was to propose a design number of gyrations $\left(\mathrm{N}_{\text {design }}\right)$ for FBM mix design. For this, aggregate mixtures with $80 \%$ of OWC (based on the $75 \%$ to $85 \%$ range established above) and different FB contents were prepared.

7 Then the mixtures were compacted to 200 gyrations and densities were plotted against number of 8 gyrations as shown in Figure 9. From the data, the number of gyrations required to reach modified 9 Proctor density was identified as can be seen in Figure 9. To study the optimum compaction effort and 10 to obtain the design number of gyrations $\left(\mathrm{N}_{\text {design }}\right)$, the changing height was recorded from the gyratory 11 compactor during compaction. From the height data, density was calculated and plotted against 12 number of gyrations (Figure 9). The marks on the curves are the target densities that were obtained 13 from modified Proctor data. It can be seen from the plots that, though the target densities were 14 different, the number of gyrations required to compact to those target densities are in a similar range. 15 That means, a design number of gyrations required to compact to modified Proctor density can be 16 established, independent of foamed bitumen content in the mixture. $\mathrm{N}_{\text {design }}$ for all FBMs considered 17 was in the range of 120-160 gyrations; 140 gyrations has therefore been selected as giving an 18 equivalence to modified Proctor. 

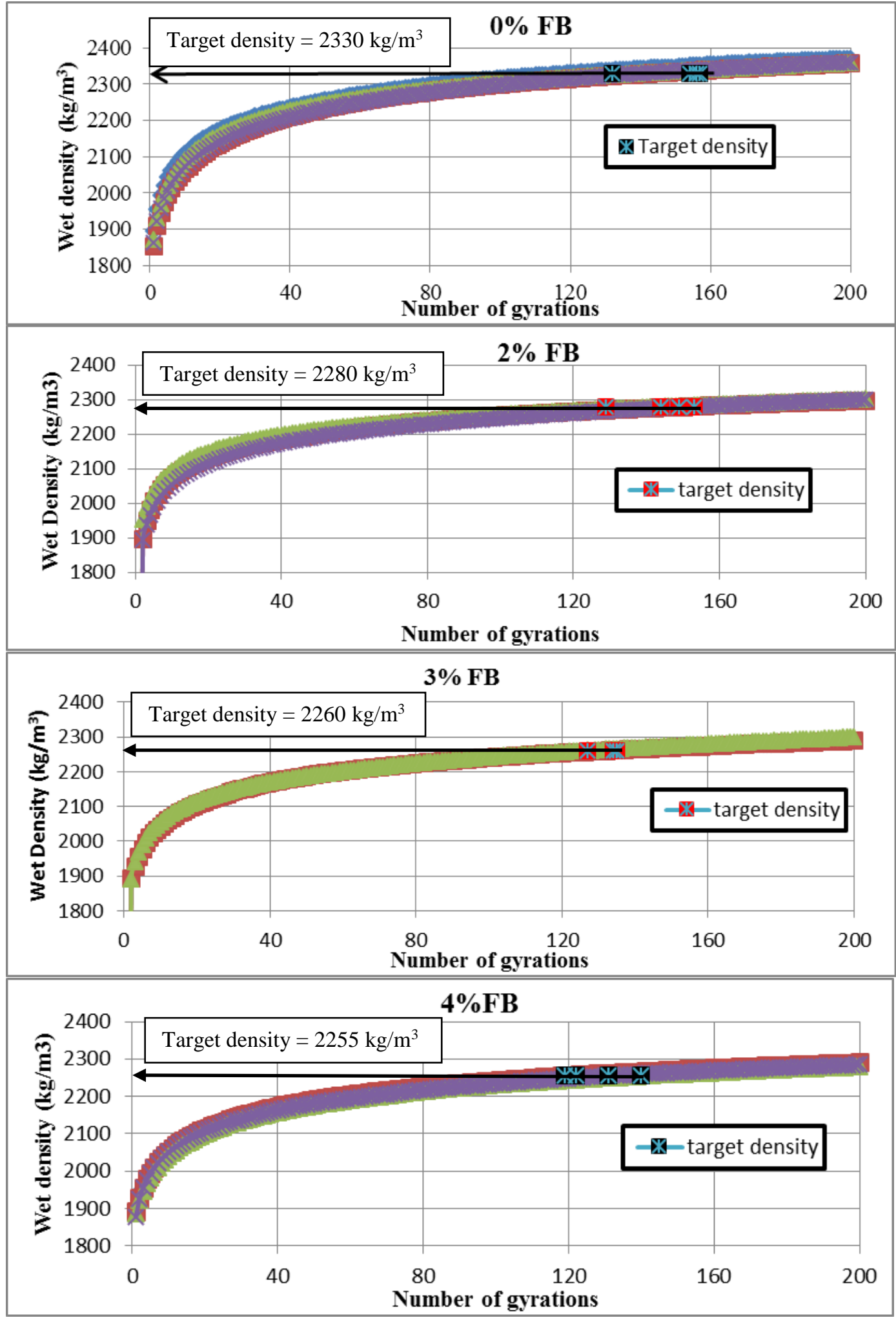

5 Figure 9 Obtaining design number of gyrations for FBM (Mixing water content of the mixture $6 \quad(\mathrm{MWC})=\mathbf{8 0} \%(\mathrm{OWC})=\mathbf{5 . 2 \%})$

\section{$7 \quad$ 3.1.2 Compactability of FBMs}

The compactability of FBMs was studied on mixtures with varying amounts of bitumen and water. As discussed previously, the modified Proctor compaction and Gyratory compaction methods were considered. The study enables the role of bitumen and water with these compaction methods to

11 be understood. As seen in Figure 10, from tests on modified Proctor compacted specimens, all curves 
give optimum water content. However, that optimum differs only slightly from one bitumen content to another, implying that the bitumen hardly contributes to the 'fluid' needed for compaction. The same effect can be seen in terms of volumetrics in Figure 11, where VMA is plotted against total fluid (water + bitumen). The optimum shifts to the right in steps and the shift is around $1 \%$ for the $2 \%, 3 \%$, $4 \%, 5 \%$ FB curves, again implying negligible contribution from the bitumen.

A similar picture is obtained from the volumetrics of gyratory compacted specimens. To study the gyratory compaction, the FBMs were compacted to 140 gyrations with an angle of gyration of $1.25^{\circ}$, compaction pressure of $600 \mathrm{kPa}$ and 30 revolutions per minute. The compactability was studied using weight-volume relationships and voids in aggregate (VMA) as calculated by Eq.1. VMA at 140 gyrations for mixtures with different bitumen content is plotted against MWC (dashed lines) in Figure 10 (each point is an average of five data points), alongside the data from modified Proctor compaction (solid lines). As can be seen from the figure, the VMA of the specimens at optimum was almost the same in the two cases, very slightly greater for modified Proctor compaction, and it increased as the foamed bitumen content increased. The optimum water content was also typically slightly higher in the case of gyratory compaction, thought to be due to the significant difference in the way the two compaction processes operate.

Overall however, the clear implication is that the bitumen gives minimal contribution during compaction and that this phenomenon is observed for both the compaction methods that were considered. Thus, the total fluid content, which has been successfully used in bitumen emulsion mix design [30-32], is not a valid parameter in FBM mix design.

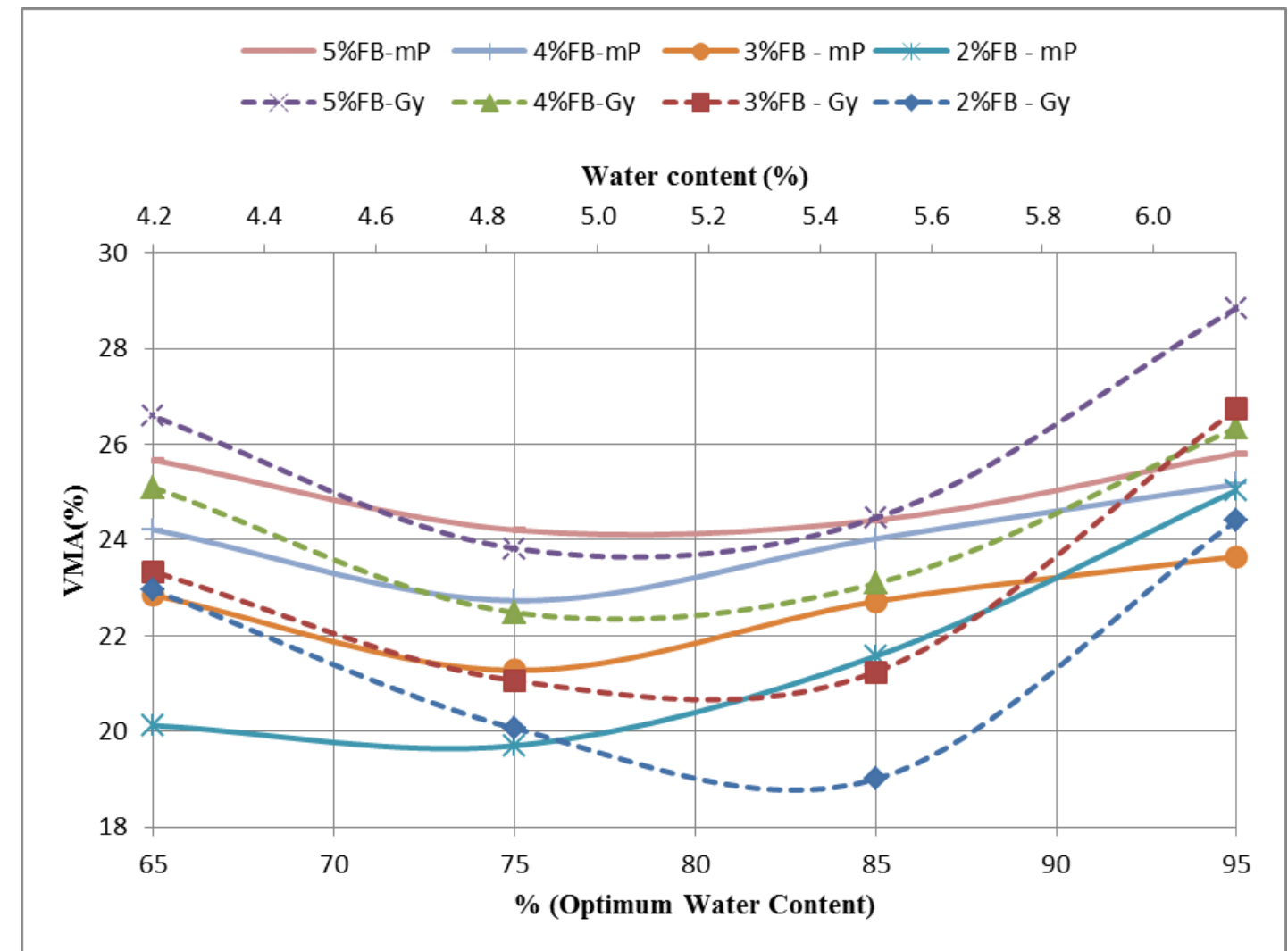




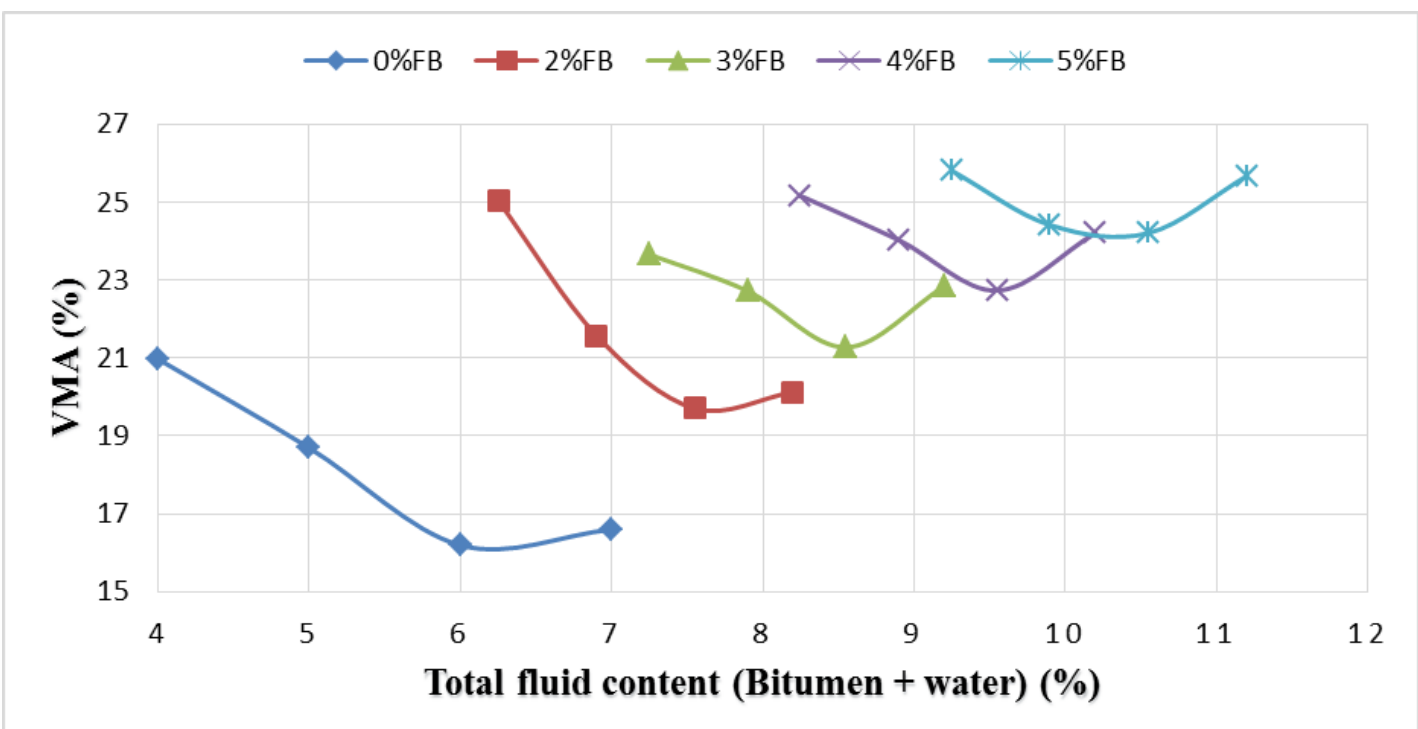

2 Figure 11 Role of bitumen and water during modified Proctor compaction

\subsection{Mechanical properties of FBMs with RAP}

The mix design parametric study discussed in the previous sections was done on mixtures with VA (100\%VA-FBM). In this section, a study has been conducted on mixtures with RAP (50\%RAPFBM and $75 \%$ RAP-FBM) to validate the proposed recommendations. To validate the MWC range proposed (75\% - 85\% of OWC), aggregates with 50\%RAP and 75\%RAP and $4 \%$ FB were mixed and compacted with varying MWC $(95 \%, 85 \%, 75 \%$ and $65 \%$ of OWC) to modified Proctor densities of similar mixtures. 4\% FB was selected as it was the design FB content obtained for 100\%VA mixes and it was assumed that the presence of RAP would not affect the design FB content (an assumption that was later shown to be incorrect). The specimens were cured as discussed for 100\%VA-FBMs. The results of mechanical tests carried out on cured specimens are presented in Figure 12. These tests were performed at ambient room temperature of $20 \pm 2^{\circ} \mathrm{C}$. ITSM values shown in figure are the average of 10 tests while ITS-dry and ITS-wet are the average of 5 tests each. As can be seen from the figure, the optima for ITSM and ITS-dry were found at 75\% of OWC and $85 \%$ of OWC respectively. For $75 \%$ RAP-FBM, optimum ITS-dry and ITS-wet were found at $75 \%$ of OWC. Although ITS-wet for 50\%RAP-FBM and ITSM for 75\%RAP-FBM didn't showed any clear optimum, other properties of both the mixtures have their optimum in the proposed range (75\% - 85\% of OWC).

To validate the $\mathrm{N}_{\text {design, }}$, the aggregates with RAP were mixed and compacted with $0 \%, 3 \%, 4 \%$ of foamed bitumen and the density data is plotted in Figure 13. For clarity the figure shows only data for $75 \%$ RAP-FBM with $0 \%$ and $3 \%$ of foamed bitumen; the data for $4 \%$ foamed bitumen lies in the same region on plot. It can be seen that the $N_{\text {design }}$ range is the same, i.e. between 80 and 120 gyrations. The mid-point of this range which is 100 was considered as $\mathrm{N}_{\text {design. }}$. The study conducted on $50 \%$ RAP-FBM gave $\mathrm{N}_{\text {design }}$ as 110 gyrations. 

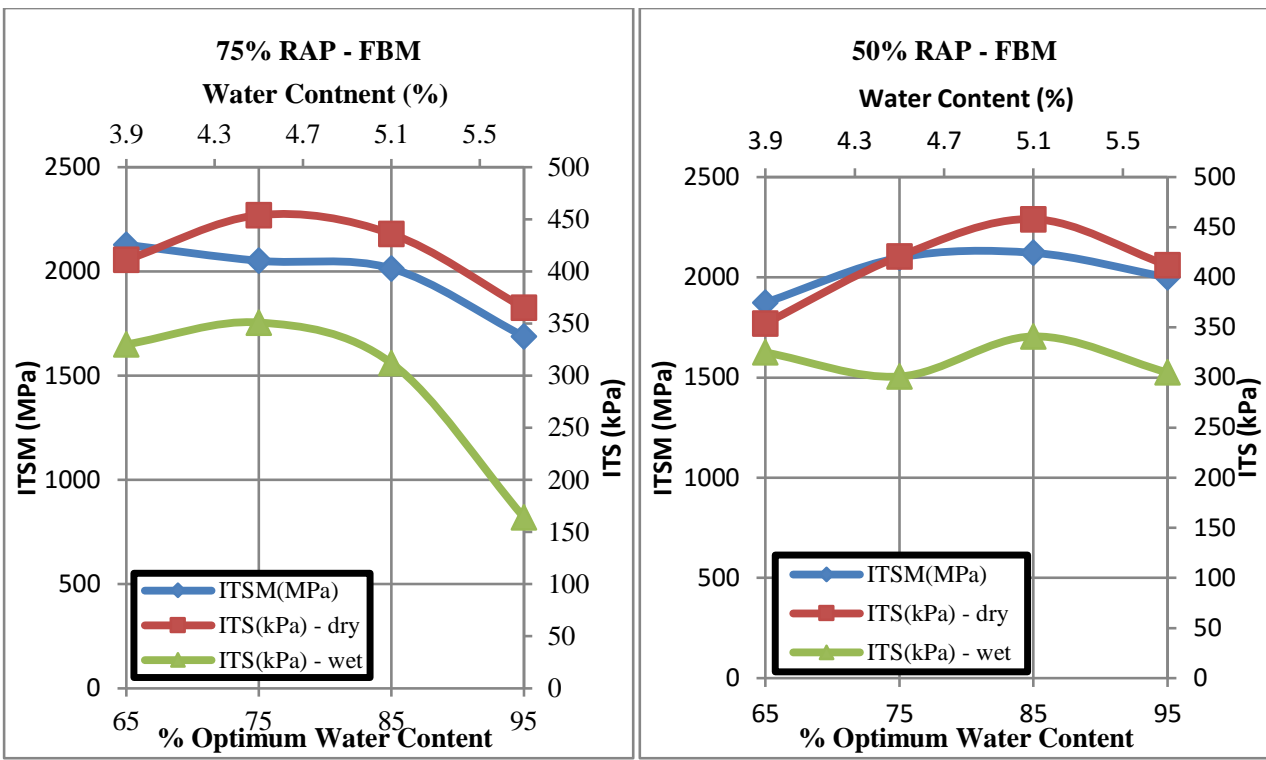

Figure 12 Mechanical properties on 50\%RAP-FBM and 75\%RAP-FBM with 4\% FB content (Validation)

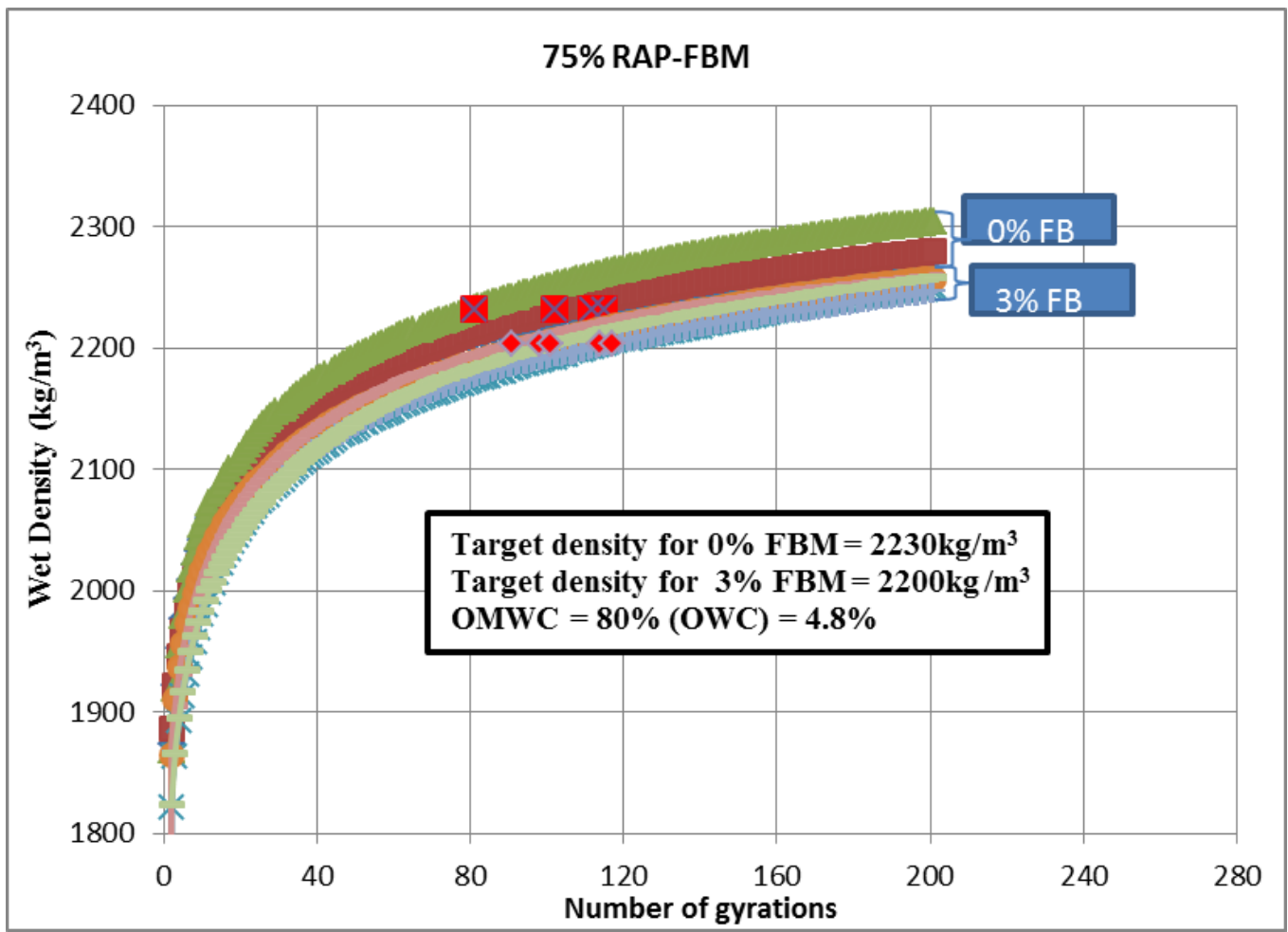

Figure 13 Validation of $\mathbf{N}_{\text {design }}$ for $75 \%$ RAP-FBM

\subsection{Foamed Bitumen (FB) content optimisation}

The results of mechanical tests on the mixtures that were compacted at optimum MWC ( $80 \%$ of

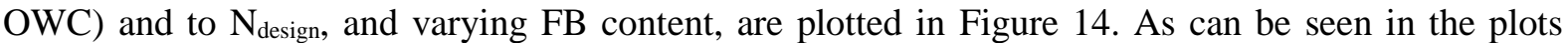
there is a clear optimum ITSM value for all mixtures. For 100\%VA mixtures, the optimum was found at $4 \%$ FB content. Similarly, the optimum ITSM values for 50\%RAP and $75 \%$ RAP mixtures were found at $3.5 \%$ and $3 \% \mathrm{FB}$ content respectively. If ITS-dry values are considered, there was no optimum for $100 \%$ VA mixtures. ITS-dry values for these mixtures increase with increasing FB content without any optimum value. However, an optimum could be located for both the mixtures with RAP (50\% RAP and 75\% RAP). The optimum values were found at 3.5\% and 3\% FB 
respectively. When ITS-wet results are considered, the optimum ITS-wet was found only for $75 \%$ RAP mixtures, which is at 3\% FB content. There was no optimum for any mixtures if ITSR (Indirect Tensile Strength Ratio) was considered. However, it can be noted that, though the maximum ITSM value was higher for $100 \%$ VA than for mixtures with RAP, most maximum ITS and ITSR values were found to be superior for mixtures with RAP. This indicates that the mixtures with RAP have better resistance against water than mixtures without any RAP. This could be attributed to the presence of fully bitumen coated RAP aggregates in the mixture. Overall, it was clear that at $4 \%$ and $3 \%$ foamed bitumen contents, optimum mechanical properties were found for $100 \% \mathrm{VA}$ and $75 \% \mathrm{RAP}$ mixtures respectively. However, optimum foamed bitumen content was less clear for 50\%RAP mixtures.
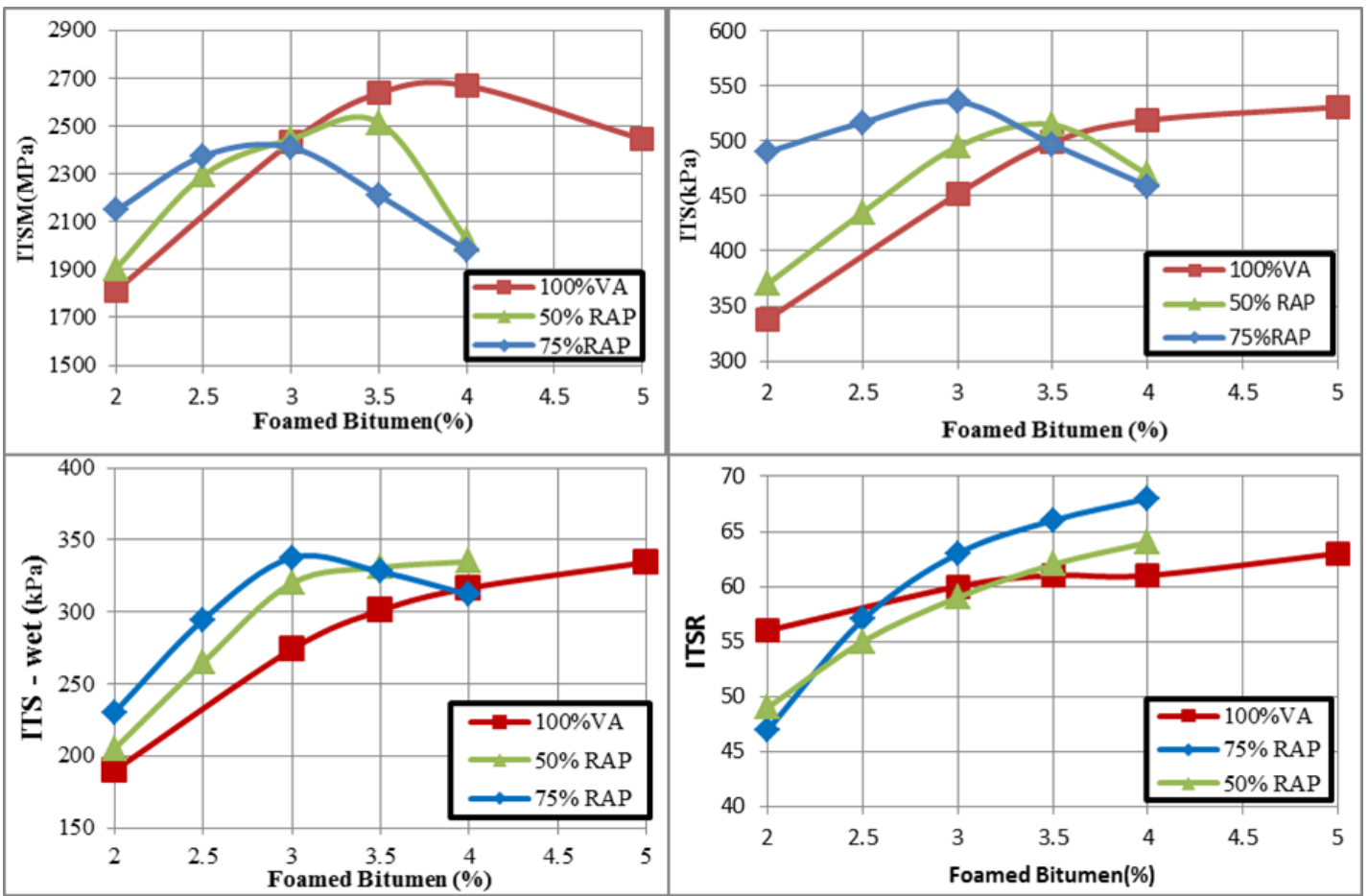

Figure 14 Mechanical properties of FBMs that were mixed at optimum MWC (80\% of OWC) and compacted to $\mathbf{N}_{\text {design }}$

\section{$14 \quad 3.4 \quad$ Effect of aggregate temperature on mechanical properties}

Temperature of the aggregate during the mixing phase influences significantly the quality of FBM [33]. Because of this reason it has been recommended to construct pavements with FBM only if the ambient temperature is above $10^{\circ} \mathrm{C}[24,25]$. As was mentioned previously, the present experimental study mostly involved mixing and compaction at an ambient temperature of $20 \pm 2^{\circ} \mathrm{C}$. However, this section has analysed the effect of aggregate temperature (which is also mixing temperature in the field) on the mechanical properties of FBM with $50 \%$ RAP aggregate (50\% RAPFBM). The mixing was carried out at three aggregate temperatures $\left(5^{\circ} \mathrm{C}, 20^{\circ} \mathrm{C}\right.$ and $\left.30^{\circ} \mathrm{C}\right)$. Before mixing, the aggregates were conditioned at the required temperature overnight (around 18 hours). The resulting temperatures of the mixtures after foaming and mixing were found to be $10^{\circ} \mathrm{C}, 26^{\circ} \mathrm{C}$ and $31^{\circ} \mathrm{C}$ respectively for aggregate temperatures of $5^{\circ} \mathrm{C}, 20^{\circ} \mathrm{C}$ and $30^{\circ} \mathrm{C}$. The mixtures were then compacted at an ambient room temperature of $20 \pm 2^{\circ} \mathrm{C}$. The mechanical tests were carried out on samples that were extracted after 24 hours and cured at $40^{\circ} \mathrm{C}$ for 72 hours ( 3 days). The results of the mechanical tests and volumetric properties of the cured specimens can be seen in Figures 15 to 16.

As can be seen in Figure 15 aggregate temperature has significance influence on compaction (air voids) and stiffness (ITSM) of the FBM. The lower aggregate temperatures resulted in inferior mixture properties. Though the difference is not significant from $20^{\circ} \mathrm{C}$ to $30^{\circ} \mathrm{C}$, the aggregate temperature of $5^{\circ} \mathrm{C}$ clearly resulted in higher air voids and less stiff mixtures. Similar results were also found when comparison was made in terms of strength (ITS-dry and ITS-wet) (Figure 16). 
Moreover the retained strengths (ITSR) increased with increase in aggregate temperature, which reinforces the finding of poor mixing and compaction at lower aggregate temperature.

The major determinate for poor mixing at low aggregate temperature is the high temperature gradient between the aggregate and the foamed bitumen which influences the rate of collapse of the foam. A high temperature gradient causes rapid collapse of the foam as the film of the bitumen bubbles is thin, which allows rapid heat transfer between foamed bitumen and aggregate. Consequently, less time is available for foamed bitumen to interact with the aggregate resulting in poor coating of the aggregate particles and inconsistent dispersion of the mastic in the mixture. As can be seen in Figure 15 the high temperature aggregates resulted in lower air voids in the resulting specimens. These higher densities (low air voids) could be associated with better compactability of the mixture at higher temperatures. As discussed the higher aggregate temperatures resulted in mixtures with relatively higher temperatures which helps in obtaining denser specimens [3, 14]. However, it has to be noted that the difference in densities between aggregate temperatures of $20^{\circ} \mathrm{C}$ and $30^{\circ} \mathrm{C}$ was found to be marginal.

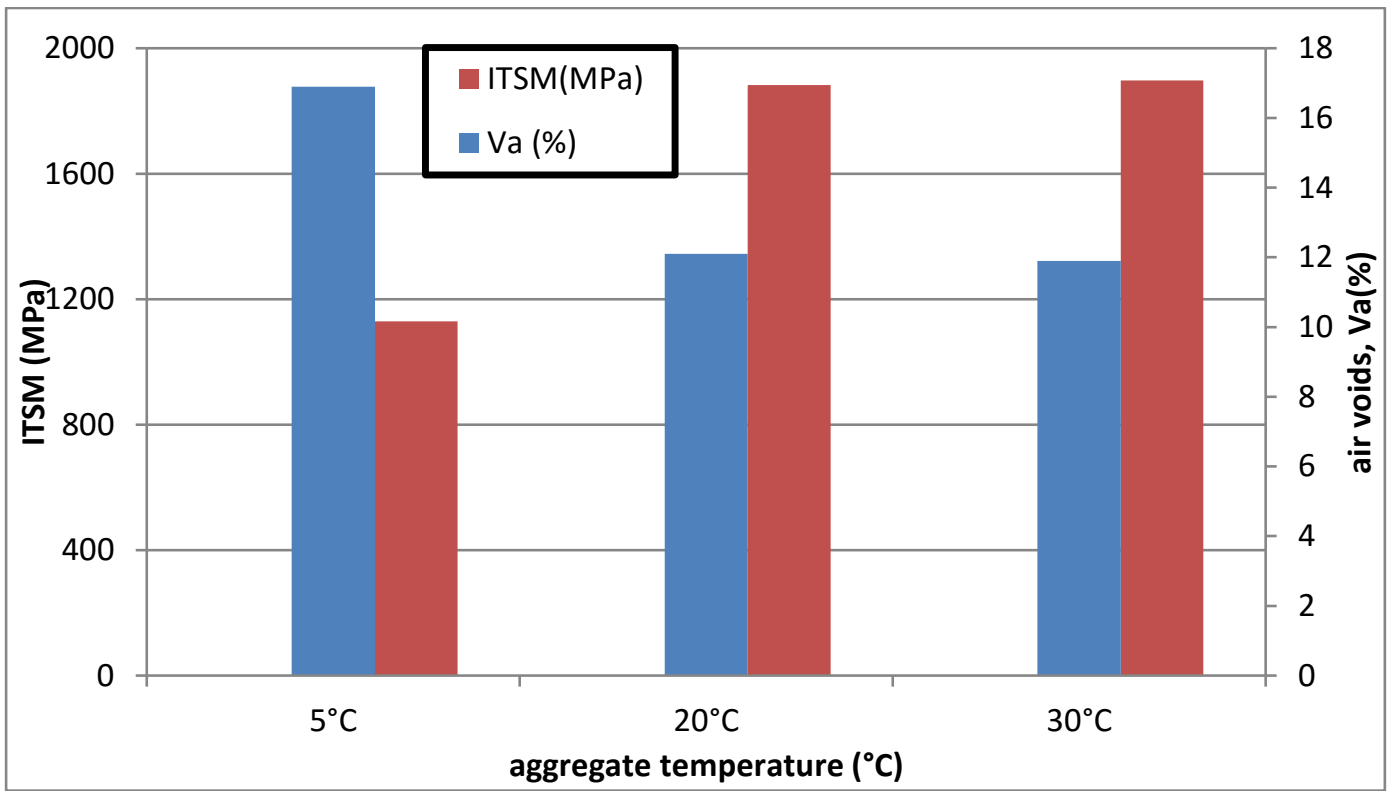

Figure 15 Effect of aggregate temperature on air voids and stiffness in 50\% RAP - FBM

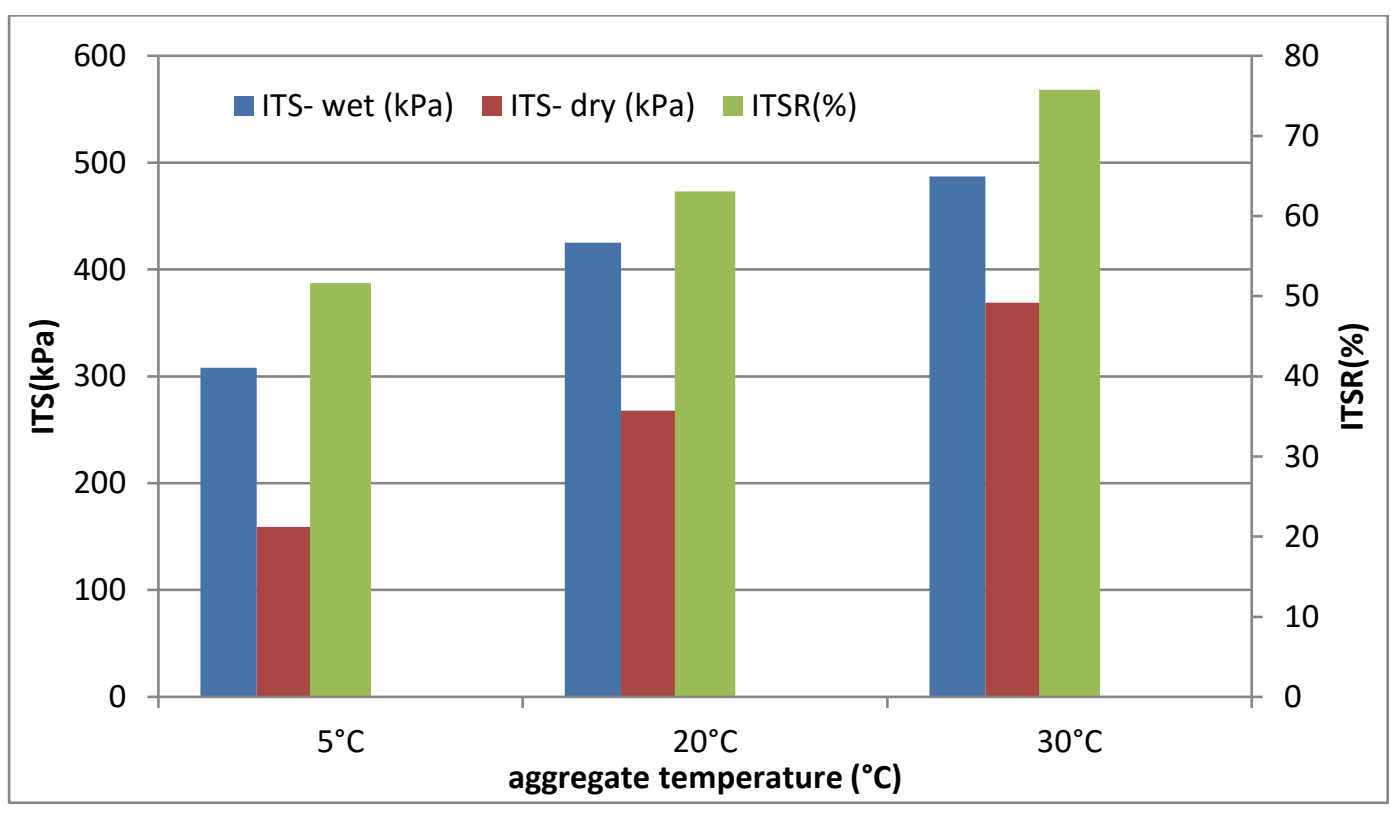




\section{CONCLUSIONS}

This paper has focussed on the development of a practical and consistent mix design procedure for FBM with the main focus being on the use of the gyratory compaction method in the proposed methodology. The study also evaluated the effect of the aggregate temperature on the mechanical properties of the FBMs. To attain this objective, the mix design parameters such as MWC and compaction effort have been optimised. This mix design parametric study was initially carried out on FBMs with virgin limestone aggregate without RAP material and a mix design procedure was proposed. The proposed methodology was later validated on FBMs with RAP. In the present study particular attention has been given to RAP characterization. The tests on recovered aggregate and bitumen revealed that the RAP was well within the homogeneity limits recommended by different agencies. A cohesion test revealed that the RAP used in this study can be classified as active.

A rational range of $75-85 \%$ of OWC obtained by the modified Proctor test was found to be the optimum range of MWC that gives optimum mechanical properties for FBMs. As this study focussed on the use of the gyratory compactor for FBM compaction, efforts were made to suggest a design number of gyrations $\left(\mathrm{N}_{\text {design }}\right)$ for optimum compaction of FBMs. It was found that a unique $\mathrm{N}_{\text {design }}$ (mixture specific) which is independent of the foamed bitumen content can be established. $\mathrm{N}_{\text {design }}$ for the virgin mixture was found to be 140 , while $\mathrm{N}_{\text {design }}$ for the mixtures with $50 \%$ of RAP and $75 \%$ of RAP was 110 and 100 respectively. It was also found that the presence of RAP influenced the design foamed bitumen content, which means that treating RAP as black rock in FBM mix design is not appropriate.

This work also evaluated the validity of the total fluid (water + bitumen) concept which is widely used in bitumen-emulsion treated mixes. It was observed that the bitumen gives minimal contribution during compaction and that this phenomenon was observed for both the compaction methods that were considered. Thus, the total fluid content, which has been successfully used in bitumen emulsion mix design is not a valid parameter in FBM mix design.

\section{REFERENCES}

1. Asphalt Academy., Bitumen Stabilised Materials:A Guideline for the Design and Construction of Bitumen Emulsion and Foamed Bitumen Stabilised Materials, 2009.

2. Wirtgen, Cold Recycling Manual, 2004.

3. Jenkins, K.J., Mix Design Considerations for Cold and Half-warm Bituminous Mixes with Emphasis on Foamed Bitumen, University of Stellenbosch, South Africa, 2000.

4. Ebels, L.J. and K.J. Jenkins. Mix design of bitumen stabilised material: best practices and considerations for classification. in 9th conference of Asphalt Pavements for South Africa, 2007.

5. Muthen, K.M., Foamed Asphalt Mixes:Mix Design Procedure, CSIR TRANSPORTEK, 1998.

6. Acott, S.M. Sand stabilization using foamed bitumen. in 3rd Conf. on Asphalt Pavements for South Africa, Durban, 1979.

7. Bowering, R.H. and C.L. Martin. Foamed Bitumen Production and Application of Mixtures Evaluation and Performance of Pavements. in Association of Asphalt Paving Technologists, 1976.

8. Kim, Y. and H. Lee, Development of mix design procedure for cold in-place recycling with foamed asphalt. Journal of Materials in Civil Engineering, Vol.18(1): p. 116-124, 2006.

9. Ramanujam, J.M. and J.D. Jones, Characterization of foamed-bitumen stabilization. International Journal of Pavement Engineering, Vol. 8: p. 111-122, 2007.

10. Sunarjono, S., The Influence Foamed Bitumen Characteristics on Cold Mix Asphalt Properties, University of Nottingham, 2008.

11. Bowering, R.H., Soil Stabilisation with Foamed Bitumen. Highway Engineering in Australia, 1971.

12. Xu, J.Z., et al., Study on the optimization design of mixing moisture content in foamed asphalt mix. Materials and Structures, Vol. 45(7): p. 1071-1085, 2012. 
13. Brennan, M., A Laboratory Investigation on the Use of Foamed Asphalt for Recycled Pavement, Joint Transportation Research Program Technical Report, Purdue University, 1983.

14. Ruckel, P.J., S.M. Acott, and R.H. Bowering, Foamed - asphalt paving mixture: Preperation of Design mixes and treatment of test specimens. Transportation Research Board, Vol. 911: p. 88-95, 1982.

15. Fu, P., et al., Investigation of the Curing Mechanism of Foamed Asphalt Mixes Based on Micromechanics Principles. Journal of Materials in Civil Engineering, Vol. 22(1): p. 29-38, 2010.

16. Lee, D.Y. Treating marginal aggregates and soil with foamed asphalt. Association of Asphalt Paving Technologists, 1981.

17. Bissada, A.F., Structural Response of Foamed-Asphalt-Sand Mixtures in Hot Environments. Transportation Research Record, Vol. 1115: p. 134-149, 1987.

18. Sakr, H.A. and P.G. Manke, Innovations in Oklahoma Foamix Design Procedures. Transportation Research Board, Vol. 1034: p. 26-34, 1985.

19. Castedo-Franco, L.H. and L.E. Wood. Stabilisation with Foamed Asphalt of Aggregate Commonly Used in Low Volume Road. in Low volume road: 3 rd International Conference, Washington, DC: Transportation Research Board, 1983.

20. Shackel, B., K. Makhiuchi, and J.R. Derbyshire. The Response of a Foamed Bitumen Stabilised Soil to Repeated Triaxial Loading in ARRB, 1974.

21. Maccarrone, S., et al. Pavement Recycling Using Foamed Bitumen. in 17th ARRB conference, Queensland, 1994.

22. Jenkins, K.J., et al. Advanced Testing for Cold Recycling Treatment Selection on N7 Near Cape Town. . in 8th Conference on Asphalt Pavements for Southern Africa (CAPSA '04), Sun City, South Africa, 2004.

23. Saleh, M.F., Effect of Rheology on The Bitumen Foamability and Mechanical Properties of Foam Bitumen Stabilised Mixes. The International Journal of Pavement Engineering 2006. 8(2).

24. Wirtgen, Cold Recycling Technology. 2010.

25. Academy, A., A Guideline for the Design and Construction of Bitumen Emulsion and Foamed Bitumen Stabilised Materials. 2009.

26. Tebaldi, G., et al., Synthesis of standards and procedures for specimen preparation and infield evaluation of cold-recycled asphalt mixtures. Road Materials and Pavement Design, 2014. 15(2): p. 272-299.

27. West, R., Willis, J.R., and Marasteanu, M.,, Improved mix design, evaluation, and materials management practices for hot mix asphalt with high reclaimed asphalt pavement content, in NCHRP 752. 2013, National Center for Asphalt Technology: Auburn, AL.

28. Petrauskas, M., Use of Cold Mix with RAP in Lithuania, in 26th International Baltic Road Conference. 2006: Kuressaare.

29. Long, F.M., H.L. Theyse, and D.F.C. Ventura, Characterization of Foamed Bitumen Treated Materials from HVS Test Sections. 2004, CSIR Transportek: Pretoria, South Africa.

30. Flintsch, G.W., R. Dymond, and J. Collura, Pavement Management Applications Using Geographic Information Systems, in NCHRP Synthesis report 335. 2004.

31. Haas, R. Reinventing the (Pavement management) Wheel. in Fifth International Conference On Managing Pavements. 2001. Seattle, Washington: Distinguished Lecture.

32. McNerney, M.T. and T. Rioux, Geographic Information System (GIS) Needs Assesment for TXDOT Pavement Management Information Systems. 2000, THE UNIVERSITY OF TEXAS AT AUSTIN.

33. Cazacliu, B., et al., Effect of Process Parameters on Foam Bitumen-based Road Material Production at Ambient Temperature. Road Materials and Pavement Design, 2008. 9(3): p. 499-523. 